\title{
Dizziness in the elderly
}

Between 20 and $30 \%$ of the world's population is known to suffer from or have suffered from dizziness, a condition which in many cases is incorrectly treated. The prevalence of dizziness is greater still among the elderly population, and the condition is the main clinical manifestation of labyrinthitis. This can lead to the impairment of the functional capacity of elderly persons, compromising quality of life, personal satisfaction and well-being.

Dizziness is a multifactorial condition that results from the cumulative effect of dysfunctions in multiple systems and results, especially among the elderly, in difficulties with performing tasks, as well as causing deficiency in the control of body balance during activities such as postural transfers, gait and other dynamic tasks that require flexion of the trunk and head due to variations in environment. This symptom is often experienced in different forms by patients, including through a false sense of movement of the body or environment, a feeling of impending fainting, feelings of instability, body imbalance, dizziness or falls and difficulties with gait.

The causes may vary and include vestibular dysfunctions (central or peripheral) and extravestibular causes such as neurological, cardiovascular, metabolic, psychogenic, visual and proprioceptive problems. The most common vestibular dysfunctions in the elderly are Benign Paroxysmal Positional Vertigo (BPPV), Meniere's Disease, Migraine Equivalents, Metabolic and Vascular Labyrinth Diseases and Multisensory Syndromes. Multiple otoneurological symptoms can result in combinations that include vertigo and other types of dizziness, changes in body balance, gait disorders, falls, tinnitus, and hearing deficits, among other conditions ${ }^{1}$.

The otoneurological evaluation of elderly persons is a comprehensive method of detecting the cause of this problem. It involves clinical evaluation, laboratory tests, imaging, caloric tests, rotational tests, audiometry, computerized posturography and the evaluation of functional capacity, body balance, gait and the impact of dizziness on the quality of life of the elderly. The therapeutic resources used to control dizziness and/or body imbalance include: etiologic treatment, pharmacotherapy, nutritional guidance, habit modification, psychotherapy, vestibular rehabilitation (VR) and, in some cases, surgical procedures ${ }^{2}$.

VR represents an important therapeutic option for body balance disorders of vestibular origin. VR is not an etiologic treatment as it does not act against the cause of the vestibular disorder, but instead promotes vestibular compensation through central neuroplasticity mechanisms. It consists of specific exercises of the eyes, head and/or body and therapeutic maneuvers in patients with benign paroxysmal positional vertigo to reposition the debris of statoconia improperly located in the ducts of the semicircular canals ${ }^{3}$. 
The integrated treatment of elderly persons with vestibular dysfunction achieves positive results through early and precise diagnosis, interdisciplinary intervention and adherence to treatment. The development of preventive programs and objective therapeutic measures are conducive to the remission or reduction of symptoms and the improvement of quality of life and functional capacity.

Juliana Maria Gazzola

Professor, Department of Physiotherapy in Human Aging, Universidade Federal do Rio Grande do Norte, Brazil.

\section{REFERENCES}

1. Doná F, Perracini MR, Gazzola JM. Avaliação físico-funcional do paciente com disfunção vestibular. In: Onishi EO, Kasse CA, Branco-Barreiro FCA, Doná F, organizadores. Avaliação e reabilitação do equilíbrio corporal: abordagem interdisciplinar. Vol. 1. São Paulo: Ektor Tsuneo Onishi; 2013. p. 47-64.

2. Ganança FF, Lopes KC, Duarte JA, Morganti, LOG, Salmito MC, Brandão PVC, et al Labirintopatias. Rev Bras Med. 2014;71:78-85.

3. Gazzola JM, Doná F. Instabilidade postural e reabilitação vestibular. In: Mendes TAB, organizador. Manuais de reabilitação do Hospital Albert Einstein. Vol. 1. São Paulo: Manole; 2014. p. 787-809. 